Florida International University FIU Digital Commons

$1-11-2002$

\title{
Fabrication considerations of a superconducting transmission line microelectromechanical switch
}

\author{
Alfredo Arturo Corrales \\ Florida International University
}

DOI: $10.25148 /$ etd.FI14061521

Follow this and additional works at: https://digitalcommons.fiu.edu/etd

Part of the Electrical and Computer Engineering Commons

\section{Recommended Citation}

Corrales, Alfredo Arturo, "Fabrication considerations of a superconducting transmission line microelectromechanical switch" (2002). FIU Electronic Theses and Dissertations. 2586.

https://digitalcommons.fiu.edu/etd/2586 
Miami, Florida

\title{
FABRICATION CONSIDERATIONS OF A SUPERCONDUCTING TRANSMISSION \\ LINE MICROELECTROMECHANICAL SWITCH
}

\author{
A thesis submitted in partial fulfillment of the \\ requirements for the degree of \\ MASTER OF SCIENCE \\ in
}

ELECTRICAL ENGINEERING

by

Alfredo Arturo Corrales

2002 
To: Dean Vish Prasad

College of Engineering

This thesis, written by Alfredo Arturo Corrales, and entitled Fabrication Considerations of a Superconducting Transmission Line Microelectromechanical Switch, having been approved in respect to style and intellectual content, is referred to you for judgment.

We have read this thesis and recommend that it be approved.

John S. Derov



Date of Defense: January 11, 2002

The thesis of Alfredo Arturo Corrales is approved.

$\begin{array}{r}\text { Dean Vish Prasad } \\ \text { College of Engineering }\end{array}$
Dean Douglas Wartzok
University Graduate School

Florida International University, 2002 


\section{DEDICATION}

I dedicate this thesis to my parents, Jose and Mireya Corrales. You have been there for me since the beginning and have played a major part in who I have become. With your support you have encouraged me to pursue my dreams. With your humor you remind me not to take myself or life too seriously. To my brother Abel I dedicate this work. You have been there for me when I needed you. You have been a mentor in my life, though you may think you had nothing to teach me. Lastly, I dedicate this to my fiancé Gaelle Even. Through the best and worst of times you have stuck right beside me. Your love and support have kept me sane through all of my life's crazy days. Thank you all for your love. 


\section{ACKNOWLEDGMENTS}

The work presented has been a two-year learning process. The two years have been an incredible experience for me and was enhanced by the persons I have encountered along the way.

A special thanks is in order to two individuals, Dr. John Derov and Dr. Robert Reid. Their wisdom and guidance has helped me to understand what it is to be a scientist. With this work came not just a need to understand the science behind it but to understand that the real world does not always fit the beautiful graphs of theory. As mentors, they were an invaluable part of my academic development.

Dr. Derov and Dr. Reid are but two of many persons which I came to know at the AFRL Sensors Directorate (AFRL/SNHA), Hanscom AFB. The rest of the people at AFRL/SNHA were incredibly helpful and willing to share their expertise. I'd like to thank Dr. Everett Crisman for his relentless correction of my methods for preparing and handling specimen as well as his assistance when repairs and replacements were needed in many of the equipment $\mathrm{I}$ have used with my experiments and measurements. Thank you Dr. Al Drehman for the high temperature superconductor specimens that you provided and your lunchtime humor. I thank Rick Webster for his insight in the field of RF measurements. He never hesitated to help me when I asked a question. I would also like to mention George Roberts who's knowledge of machining and close ties with the machine shop on the base made it so that anything that I had to have fabricated for me was done correctly and accurately. Thanks to him I have a deeper understanding and appreciation for the many machining tools needed in building the specialized fixtures and 
parts we've used. Support at AFRL/SNHA extends to the executive personnel as well as the scientist. I'd like to thank Livio Poles, Dave Curtis, and Steve Mittleman for their support of me, my project, and especially the scientist I have been working with. This is not everyone at AFRL/SNHA or at Hanscom AFB because if I did that, this thesis would be another 106 pages long. I am grateful to everyone who took the time to answer my questions, provide support and make me feel at home.

I want to thank FIU for their support. My stay in Boston was made possible by a large group of persons working both in the College of Engineering and in the Comptroller's office, but above all the FAST Center. I am forever grateful to the FAST Center. Their support financially, academically, and personally for me and my project were key to my success. Dr. Grover Larkins, my main advisor believed in me and had high expectation. Thank you for all that you have done for me. Thanks to Dr. Vlassov who ran around the University and got all of my papers signed. Whether they were a tuition waiver or a travel reimbursement, he got the paperwork to who ever it was supposed to go to. Thank you Pat Brammer, the head secretary in the Electrical and Computer Engineering department. Without her I don't know how I would have been registered in time for classes.

In the College of Engineering, I would like to recognize the dean's office for their understanding of my situation and providing me help when possible. I'd also like to thank Mercy Rueda who is the Director of the FEEDS program. While in Boston, I was able to complete my class work at a distance thanks to her and the FEEDS program. 
My final acknowledgement goes to Dr. Harold Weinstock. His financial support of the FAST Center by way of the Air Force Office of Scientific Research grant \# F49620-95-1-0519 made it possible for me to work closely with a section of the Air Force Research Laboratory.

This experience has been wonderful. It has allowed me to grow both as a scholar and a human being. Thanks to everyone involved and thanks to God. 


\begin{abstract}
OF THE THESIS
FABRICATION CONSIDERATIONS OF A SUPERCONDUCTING

TRANSMISSIONLINE MICROELECTROMECHANICAL SWITCH

by

Alfredo Arturo Corrales

Florida International University, 2002

Miami, Florida

Professor Grover L. Larkins, Major Professor
\end{abstract}

Developing technologies have always faced the same problems. New applications require smaller systems, must consume less power, and provide greater sensitivity than what is currently available. This thesis provides crucial data for the manufacturing of a microelectromechanical (MEM) switch on a superconducting transmission line. New applications of front-end antennas require small, low-loss switches. MEM switches have shown insertion losses less than $0.1 \mathrm{~dB}$ and isolation of $50 \mathrm{~dB}$ at RF frequencies. Superconducting transmission lines can provide circuits with extremely low attenuation. The combination of the two can provide the best system for the need of these new applications. This thesis had two goals. The first was to create a process for the fabrication of a MEM switch on a superconductor based circuit. The second was to provide information on the individual process steps with special attention on the compatibility of the superconductor, $\mathrm{YBa}_{2} \mathrm{Cu}, 0,{ }_{7}$, with the fabrication steps. Both of these goals have been achieved and a fabrication process was successfully designed that can be used to fabricate a MEM capacitive switch on $\mathrm{YBa}_{2} \mathrm{Cu} ; 0, \ldots 7$. 


\section{TABLE OF CONTENTS}

CHAPTER

PAGE

1 INTRODUCTION 1

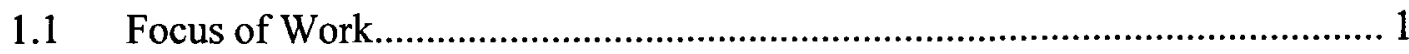

$1.2 \quad$ Progress In MEM Switch Fabrication...................................................... 2

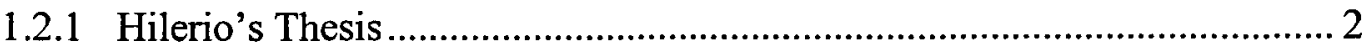

1.2.2 Switch Design and Simulation.............................................................. 3

1.2.3 Fabrication Process Development............................................................. 4

1.2.4 Compatibility Between $\mathrm{YBa}_{2} \mathrm{Cu}_{3} \mathrm{O}_{\mathrm{x}-7}$ and Fabrication Processes.............. 7

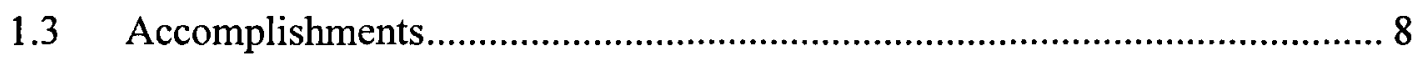

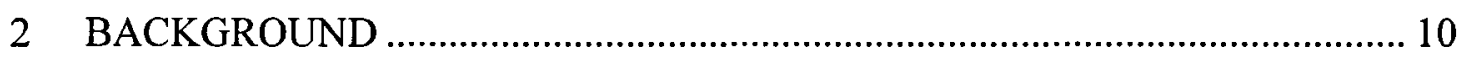

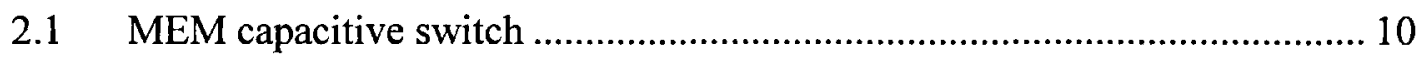

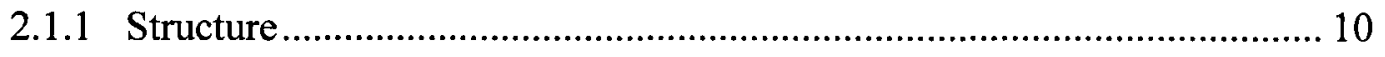

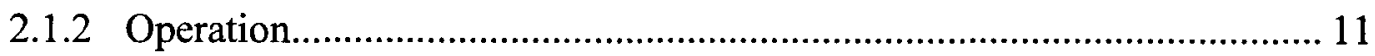

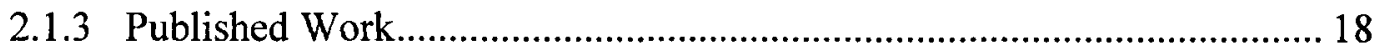

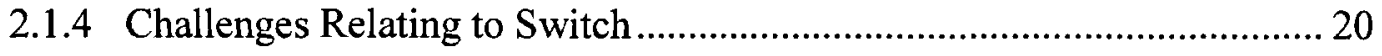

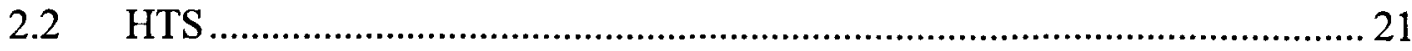

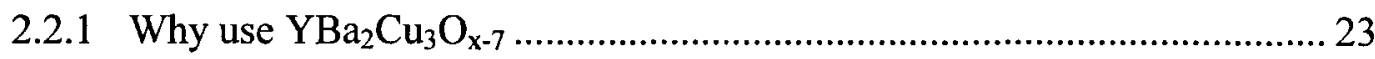

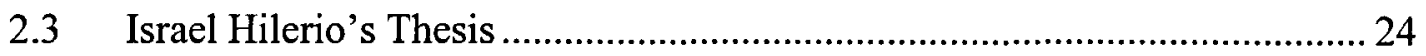

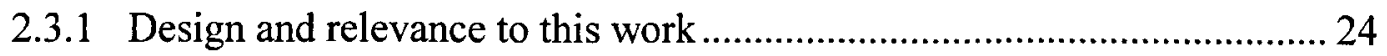

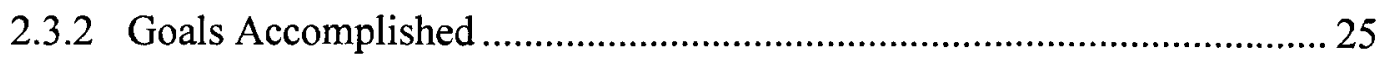

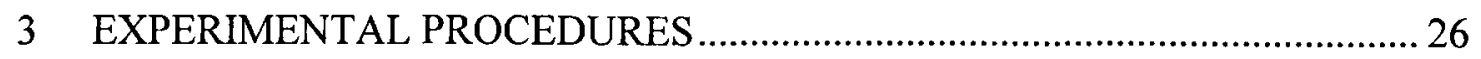




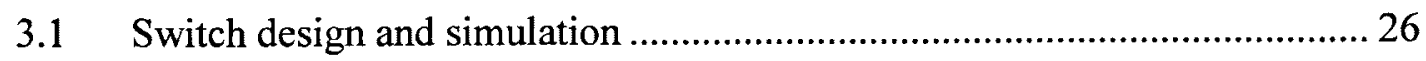

3.1.1 Transmission line possibilities......................................................... 26

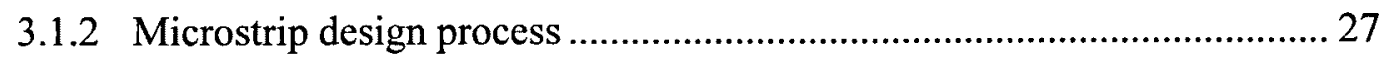

3.1.3 Electromagnetic Simulation ........................................................... 28

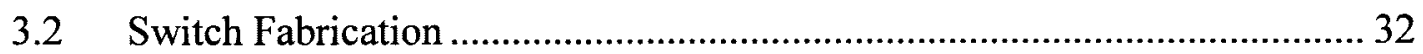

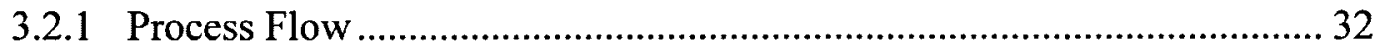

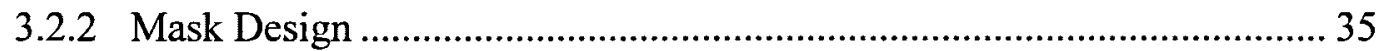

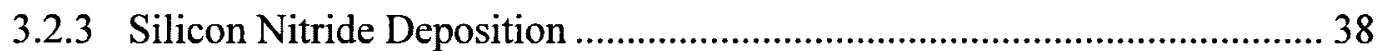



3.2.5 Single Layer Photoresist Deposition and Patterning ............................. 42

3.2.6 Dual layer Photoresist/LOR Deposit and Patterning …......................... 43

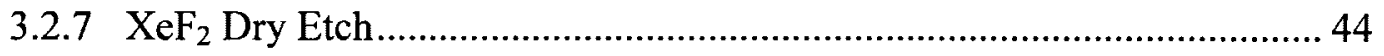

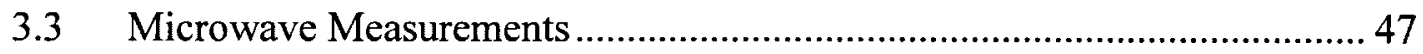

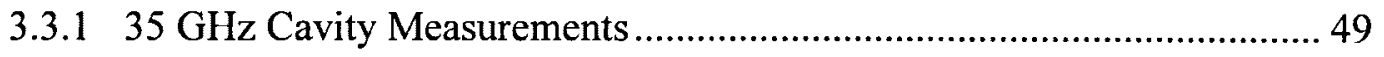

3.3.2 3.5 GHz Half-wave Microstrip Resonator Measurements...................... 51

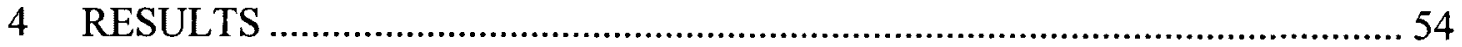

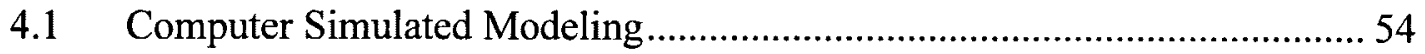

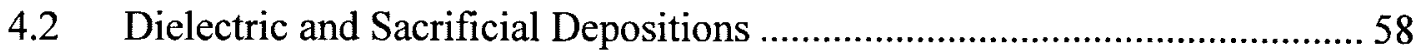

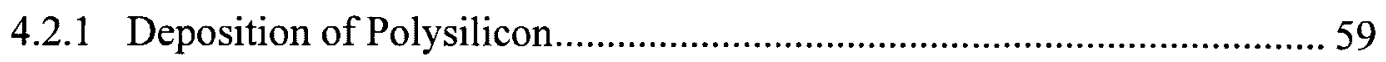

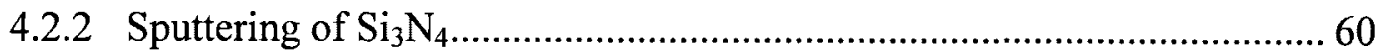

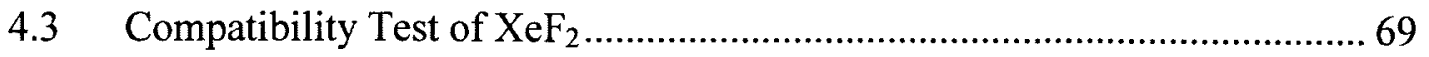

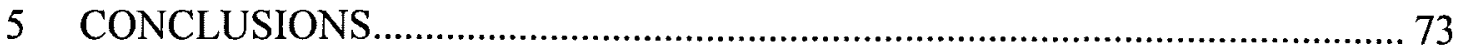




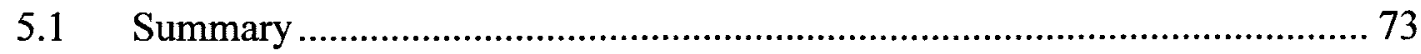

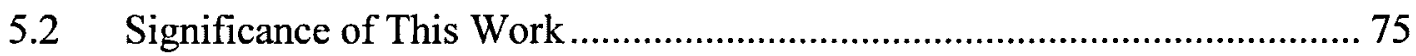

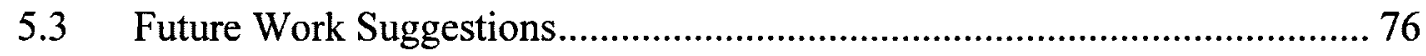

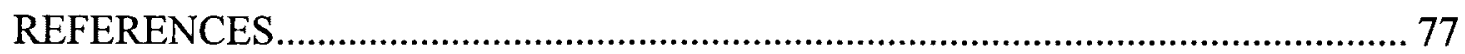

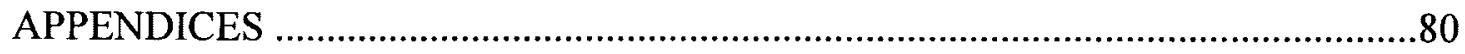




\section{LIST OF FIGURES}

FIGURE

PAGE

Figure 2.1 - Diagrams of basic MEM Capacitive Switch Structure. (a) Cantilever Switch Structure (b) Air Bridge Switch Structure

Figure 2.2 - Diagram representation of capacitance equivalent for the switch's dielectric capacitance. (a) Switch in unactuated, Up State (b) Switch in actuated, down state

Figure 2.3 - (a) Illustration of forces at work during actuation of switch. Fr and Fe represent restoration and electrostatic forces respectively. (b) Graph of the deflection of a $300 \mu \mathrm{m}$ beam with varying voltages from $0 \mathrm{~V}$ to $45 \mathrm{~V}$...... 16

Figure 2.4 - Typical actuation responses from a MEM Capacitive switch

Figure 3.1 - Cross Sectional and 3D View of 3 Types of Transmission Lines. (a) Coplanar Waveguide, (b) Microstrip, (c) Stripline

Figure 3.2 - Cross Section View of Microstrip Transmission Line. Labeling indicates major parameters contributing to Characteristic Impedance Zc. Substrate assumed anisotropic so $\epsilon \mathrm{r}=\epsilon \mathrm{y}=\epsilon \mathrm{x}$. Sidewalls assumed to be perfect conductors and width $« \mathrm{~d} / 2$.

Figure 3.3 - MEM switch and circuit design chosen for fabrication. Diagram includes typical dimensions for the switch and transmission line. (a) Two dimensional top view of the switch. (b) Angled 3 dimensional rendering of switch.

Figure 3.4 - Three different designs considered for MEM switch circuit........................ 31

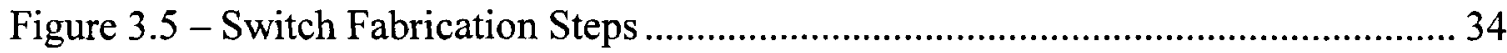

Figure 3.6 - "YBCO" Mask with several alignment markers pointed out and highlighted(a) View of full mask pattern with four alignment markers highlighted.(b) Close up view of two microstrip circuits with the separating alignment marker highlighted.

Figure 3.7 - "Dark Field Sacrificial" Mask (a) Full view of mask, (b) Closer view of two distinct circuit patterns on the mask.

Figure 3.8 - "Metal" Mask (a) Full view of mask, (b) Closer view of two distinct circuit patterns on the mask. 
Figure 3.9 - Xenon Difluoride Etching System Schematic (a) Physical system Layout

Figure 3.10 - Microwave Measurement System Schematic. Same system setup is used for the $35 \mathrm{GHz}$ cavity resonator measurements and the $3.5 \mathrm{GHz}$ microstrip resonator measurements.

Figure 4.1 - Comparison between Si3N4 and BaTiO3 Simulations MEM Switch Simulations.

Figure 4.2 - Scattering parameter for an HTS microstrip MEM capacitive switch on a 10 mil thick $\mathrm{LaAlO}_{3}$ substrate. The metal beam for this model was $100 \mu \mathrm{m}$ wide and $200 \mu \mathrm{m}$ long. $\mathrm{BaTiO}_{3}$ was used as the insulative layer with $\epsilon_{\mathrm{r}}=300$. (a) Depicts the transmitted (S21) power response. (b) Depicts the reflected (S11) power response.

Figure 4.3 - Magnified view of S21 response for the MEM switch down state. Switch shows losses less than $-0.1 \mathrm{~dB}$ for frequencies up to $18 \mathrm{GHz}$. 58

Figure 4.4 - Graph comparing initial measurements of coated and uncoated Superconductor specimens. Resistance values have been standardized to reflect $3.5 \mathrm{GHz}$ responses.

Figure 4.5 - RGA Scan of UHV Chamber while chamber is being pumped by cryopump. Water has an atomic weight of 18 . Its chemical representation is seen in the graphas the large peak and the two smaller peaks to the left. The graph confirms that water is the largests gaseous component in the chamber but the amount is very small.

Figure 4.6 - This graph is an RGA scan of the UHV chamber after closing off the cryopump from the chamber. Since the cryopump is closed off the chamber slowly creeps up in pressure and the residual gas composition changes. The graph shows argon, the large peak, as having the largest chemical signature

Figure 4.7 - This RGA scan shows the gas composition in the chamber after the turbo pump begins.

Figure 4.8 - Comparison of coated and uncoated superconductor specimens with adjustment to Si3N4 deposition process. Resistance values standardized to reflect $3.5 \mathrm{GHz}$ response.

Figure 4.9 - Tangental losses of copper specimens coated with either $\mathrm{BaTiO} 3$ or Si3N4. Response of $1 / \mathrm{Qd}$ to temperature 
Figure 4.10 - XeF2 Etch of Silicon Dice. Top drawings show the 3 dimensional rendering of the etched silicon die. The bottom are charts displaying the cross sectional profile of the corresponding die.............................................. 7

Figure 4.11 - Microwave Measurements Before and After XeF2 Etch of YBCO.......... 72 


\section{Introduction}

\subsection{Focus of Work}

The search for advanced technologies has led to innovations in many fields. At times, unrelated fields have been brought together to create products of great merit. This thesis focuses on the development of a fabrication process for a Microelectromechanical (MEM) switch that will be compatible with a High Temperature Superconducting (HTS) thin film. Computer modeling was incorporated with the work begun by Hilerio to construct a fabrication process [1]. The individual steps in the process were then tested for compatibility and adjusted for optimum performance on the available equipment.

This research has been conducted because of the advantage achievable by the combination of the two mentioned technologies. MEM switches offer low insertion loss with a minimal amount of power for activation [2][3] and are also compatible with Monolithic Microwave Integrated Circuit (MMIC) fabrication. HTS thin films offer superconducting properties at temperatures above $77 \mathrm{~K}$. This provides extremely low loss transmission lines that function at liquid nitrogen temperatures. Placement of a MEM switch on an HTS transmission line will provide components with higher performance than currently available devices. These devices are advantageous for implementation in switchable filters and phase shift circuit applications.

Hilerio's thesis [1] provided the fundamentals for MEM switch fabrication. His work showed that MEM technology can be fabricated and tested using the equipment available. The work presented here represents the continuation of the MEM switch research. First, the switch was redesigned for use on a microstrip configuration. Next, a fabrication process was developed to incorporate a superconducting thin film. Then, the individual 
steps in the process were iterated and refined. Finally, tests were conducted to show that the process steps were compatible with the $\mathrm{YBa}_{2} \mathrm{Cu}_{3} \mathrm{O}_{\mathrm{x}-7}$ thin films. Problems mentioned by Hilerio were taken into consideration and alternative methods introduced to solve them.

\subsection{Progress In MEM Switch Fabrication}

\subsubsection{Hilerio's Thesis}

Hilerio had previously performed work on MEM switches that led to his master's thesis. He was able to successfully fabricate a MEM switch on a microwave transmission line using conventional materials. Using a Coplanar Waveguide (CPW) design for the transmission line, he proceeded to fabricate both the CPW and the switch from gold. The structure was fabricated on top of a gallium arsenide (GaAs) substrate. The switch was designed as a metal beam stretching over the center conductor and anchored at either side to the ground planes. The contact area of the conductor was coated with a dielectric to provide a metal-insulator-metal contact. His work included both the fabrication process and analysis of the switch performance.

Final fabrication of the MEM switches included variations in the beam length. Among the switches, one was chosen to provide a full analysis of the MEM switch performance. A switch with beam measuring $270 \mu \mathrm{m}$ long by $120 \mu \mathrm{m}$ wide was used for these measurements. A pull-down voltage of $35 \mathrm{~V}$ actuated the switch from the up to the down position. Isolation and insertion losses were measured in the up and down position of the switch with values ranging from $1 \mathrm{GHz}$ to $16 \mathrm{GHz}$. At $10 \mathrm{GHz}$ the insertion loss was measured as $0.15 \mathrm{~dB}$ while an isolation of $22 \mathrm{~dB}$ was achieved. 
Hilerio's work shows that a MEM switch can be fabricated with the available

facilities. In his thesis, Hilerio discussed some of the areas that need improvement. Two major obstacles that were mentioned involved the sacrificial PMGI polymer. To remove the polymer a wet release process is required. The wet release process functions poorly in removing the PMGI and, at times, causes sticking of the beam. The PMGI also has a limited temperature range. These two problems make the fabrication process less reliable and restrict the thermal range of any further processes. The use of an HTS thin film was also suggested by Hilerio as the next step in the development of the switches. These fabrication issues were taken into consideration and work was done on the development of the necessary process. The following sections give a summary of the challenges confronted in this investigation.

\subsubsection{Switch Design and Simulation}

Most MMICs use microstrip transmission lines. Thus, Hilerio's switch was reconfigured as a series switch in a microstrip transmission line. In the down position the switch forms a short circuit and the signal is transmitted with minimal losses while in the up position the switch is an open circuit causing the signal to be reflected. The switch design was approached at an elementary level.

The switch designs were modeled using Sonnet to provide a basic understanding of the switch performance. The results confirmed the findings from the literature [1][2]. The switch is expected to have insertion losses of $0.1 \mathrm{~dB}$ in the down position at $6 \mathrm{GHz}$ and can be expected to provide isolation of $8 \mathrm{~dB}$ in the up position at the same frequency. It was also made apparent from the results that the attempted modifications to the 
transmission line were not crucial for the switch performance. Instead, the largest change in performance was due to the deviation in the width and length of the metal beam.

\subsubsection{Fabrication Process Development}

Changes were made to the fabrication process with the intent of providing a better product. Hilerio's concerns have been addressed in this work by providing an HTS thin film as the conductor for the transmission line, replacing the polymer sacrificial layer with polysilicon, and developing a gas phase release process.

$\mathrm{YBa}_{2} \mathrm{Cu}_{3} \mathrm{O}_{\mathrm{x}-7}$ was used to replace the gold transmission line and $\mathrm{LaAlO}_{3}$ replaced the GaAs. The substrate was changed because HTS thin film depositions are not compatible with the GaAs substrate. The addition of the HTS film did create questions that needed answering. In particular, how was the material going to interact with other compounds and process steps? Addressing these questions is one of the principal thrusts of this thesis. The silicon sacrificial layer replaced the PMGI polymer process. This change of material in combination with the $\mathrm{XeF}_{2}$ etch release addressed the two obstacles that Hilerio had mentioned in his conclusions.

\subsubsection{Use of $\mathrm{YBa} 2 \mathrm{Cu} 3 \mathrm{Ox}-7$ for HTS transmission line}

$\mathrm{YBa}_{2} \mathrm{Cu}_{3} \mathrm{O}_{\mathrm{x}-7}$ was chosen as the superconducting material. This HTS was used because two labs could provide films. Both the F.A.S.T. Center at FIU and the AFRL Sensors Directorate at Hanscom AFB had facilities that worked on this. The specimens were produced using two different deposition methods.

$\mathrm{YBa}_{2} \mathrm{Cu}_{3} \mathrm{O}_{\mathrm{x}-7}$ is an HTS having a typical critical temperature $\left(\mathrm{T}_{\mathrm{c}}\right)$ around $90 \mathrm{~K}$. The high $T_{c}$ value means that the devices fabricated using this material function well above 
the evaporation temperature of nitrogen and thus liquid nitrogen can be used to cool them during operation. A high $\mathrm{T}_{\mathfrak{c}}$, especially above liquid nitrogen, simplifies this work's migration to industrial use. The specimens from FIU and Hanscom varied in their measured $T_{c}$ values. Individual specimens' $T_{c}$ ranged from $85 \mathrm{~K}$ to $92 \mathrm{~K}$.

Finally, the $\mathrm{YBa}_{2} \mathrm{Cu}_{3} \mathrm{O}_{\mathrm{x}-7}$ was the most attractive material because among the HTS it has the largest amount of background literature. Other HTS films have been less thoroughly investigated; consequently it is more difficult to find information on them and preferable to use a well-tested material. It is important to note that all superconductors are not the same and do not react in an identical fashion to processing. The work performed here is exclusively done with $\mathrm{YBa}_{2} \mathrm{Cu}_{3} \mathrm{O}_{\mathrm{x}-7}$. Fabrication results would differ with the use of other materials.

\subsubsection{XeF2 Gas Phase Etching}

The use of the $\mathrm{XeF}_{2}$ etch in processing the $\mathrm{MEM}$ switch came about from the need to redesign the metal beam fabrication steps. Until now, the liftoff process to remove the polymer from underneath the metal beam involved a wet etch. Two major problems have been encountered using this technique. One, the solvent takes a long time to dissolve the polymer completely. In some cases plasma ashing is needed to remove residual polymer. Two, the fluid tension of the solvent occasionally causes the beam to flex and stick to the remaining polymer. This renders the switch useless and reduces the reliability of the fabrication process. The $\mathrm{XeF}_{2}$ process offers a solution to both problems since $\mathrm{XeF}_{2}$ has a high etching rate for silicon and performs the task in the gas phase. 
The use of $\mathrm{XeF}_{2}$ has been studied and is commonly used in both bulk and surface micromachining. Research has shown that, unlike F-atom etching, $\mathrm{XeF}_{2}$ is a very selective etchant that targets intrinsic Si while exhibiting limited or no reaction with silicon dioxide $\left(\mathrm{SiO}_{2}\right)$ [4]. The selectivity of $\mathrm{XeF}_{2}$ extends to other silicon compounds as well as other materials such as $\mathrm{LaAlO}_{3}$, aluminum, and photoresist [5][6]. The effects of $\mathrm{XeF}_{2}$ interactions with $\mathrm{YBa}_{2} \mathrm{Cu}_{3} \mathrm{O}_{\mathrm{x}-7}$ were previously unknown. This work provided strong evidence that $\mathrm{XeF}_{2}$ does not damage the $\mathrm{YBa}_{2} \mathrm{Cu}_{3} \mathrm{O}_{\mathrm{x}-7}$.

\subsubsection{Polysilicon and Silicon Nitride Depositions}

Deposition processes for polysilicon and silicon nitride were developed using magnetron sputtering. The polysilicon procedure replaced the use of PMGI as a sacrificial layer. The film was deposited in an argon atmosphere. $\mathrm{Si}_{3} \mathrm{~N}_{4}$ was one of two dielectrics to be investigated for compatibility with $\mathrm{YBa}_{2} \mathrm{Cu}_{3} \mathrm{O}_{\mathrm{x}-7} . \mathrm{Si}_{3} \mathrm{~N}_{4}$ deposition differed from the polysilicon deposition because it was deposited by reactive sputtering in an argon/nitrogen atmosphere. The two procedures encountered similar problems because both used silicon targets to deposit the desired films.

The research concluded that the presence of oxygen and/or water in the vacuum chamber was responsible for tainting the deposited films. When contaminated, both depositions were noticeably affected. The polysilicon showed no etching in the presence of $\mathrm{XeF}_{2}$ while the $\mathrm{Si}_{3} \mathrm{~N}_{4}$ had a lower than expected index of refraction and high microwave losses. To correct for this problem, steps were taken in both cases to reduce the presence of oxygen in the chamber. The two depositions were attempted using both $\mathrm{RF}$ and DC power supplies. The rate of deposition was much higher using RF. 


\subsubsection{Compatibility Between $\mathrm{YBa}_{2} \mathrm{Cu}_{3} \mathrm{O}_{\mathrm{x}-7}$ and Fabrication Processes}

It is critical that the switch fabrication process not damage the HTS thin film. Most of the processes are standard and recognized as benign to $\mathrm{YBa}_{2} \mathrm{CuO}_{\mathrm{x}-7}$. However, the effect associated with the deposition of the dielectrics $\mathrm{Si}_{3} \mathrm{~N}_{4}$ and $\mathrm{BaTiO}_{3}$ directly on the $\mathrm{YBa}_{2} \mathrm{Cu}_{3} \mathrm{O}_{\mathrm{x}-7}$ and the effects associated with the interaction between $\mathrm{XeF}_{2}$ and $\mathrm{YBa}_{2} \mathrm{Cu}_{3} \mathrm{O}_{\mathrm{x}-7}$ were not previously known. Thus, testing of the $\mathrm{YBa}_{2} \mathrm{Cu}_{3} \mathrm{O}_{\mathrm{x}-7}$ films before and after processing was necessary. The dielectric deposition caused attenuation of the microwave response in the HTS films. These losses were measured and the corresponding surface resistance was extrapolated. The results show that both dielectrics have reasonable losses and can be used in the process without hindering the switch performance.

\subsubsection{Effects from Dielectric Deposition on $\mathrm{YBa}_{2} \mathrm{Cu}_{3} \mathrm{O}_{x-7}$}

For the MEM switch to work reliably it is necessary to deposit an insulating dielectric layer between the contact area of the HTS and the metal beam. Two dielectric materials were investigated for their unique properties. $\mathrm{Si}_{3} \mathrm{~N}_{4}$ has a high dielectric strength while $\mathrm{BaTiO}_{3}$, a ferroelectric at low temperatures, is known to have a high dielectric constant. Each of the dielectrics offers one desirable property. A high dielectric strength means that higher voltages can be used without breakdown. A high dielectric constant provides a material with lower microwave loss.

Microwave measurements of the HTS specimens before and after the dielectric depositions verified two important properties of the dielectrics when deposited on the HTS. One, the $\mathrm{YBa}_{2} \mathrm{Cu}_{3} \mathrm{O}_{\mathrm{x}-7}$ had minimal interaction with the dielectric coatings during 
the deposition. Two, the attenuation of the dielectrics is low enough that they can be considered for application directly on $\mathrm{YBa}_{2} \mathrm{Cu}_{3} \mathrm{O}_{\mathrm{x}-7}$. The microwave measurements provided a way to calculate the surface resistance of the specimens with and without a dielectric, showing the effects of the depositions.

\subsubsection{2 $\mathrm{XeF}_{2}$ Etching Process Compatibility}

Before the $\mathrm{XeF}_{2}$ process could be integrated into the proposed fabrication process it was necessary to insure that the $\mathrm{XeF}_{2}$ selectively etched the polysilicon. Previous literature did not comment on how the $\mathrm{XeF}_{2}$ process would react with $\mathrm{YBa}_{2} \mathrm{Cu}_{3} \mathrm{O}_{\mathrm{x}-7}$. The understanding of the relationship between $\mathrm{XeF}_{2}$ and $\mathrm{YBa}_{2} \mathrm{Cu}_{3} \mathrm{O}_{\mathrm{x}-7}$ is vital since a reaction could damage the $\mathrm{YBa}_{2} \mathrm{Cu}_{3} \mathrm{O}_{\mathrm{x}-7}$.

Tests were performed in a custom $\mathrm{XeF}_{2}$ etching system. A set of parameters was chosen that are known to etch the silicon specimens. Then, samples at every process step from the bare $\mathrm{LaAlO}_{3}$ substrate to the dielectric coated HTS specimens were tested in the chamber. Special attention was placed on the $\mathrm{YBa}_{2} \mathrm{Cu}_{3} \mathrm{O}_{\mathrm{x}-7}$ because of its sensitive nature. The tests showed that $\mathrm{XeF}_{2}$ is compatible with all the switch materials but care must be taken when $\mathrm{YBa}_{2} \mathrm{Cu}_{3} \mathrm{O}_{\mathrm{x}-7}$ is present. It has been shown that this process can be integrated with the prescribed fabrication process but alterations to the fabrication process should be made carefully especially with regard to the $\mathrm{YBa}_{2} \mathrm{Cu}_{3} \mathrm{O}_{\mathrm{x}-7}$.

\subsection{Accomplishments}

With completion of this work, a complete process flow is available for the fabrication of a superconducting transmission line MEM switch. Computer modeling has been done with results matching reported values of similar work. A polysilicon and a $\mathrm{Si}_{3} \mathrm{~N}_{4}$ 
deposition process have been developed. Development of a $\mathrm{XeF}_{2}$ etch process in combination with the polysilicon deposition offer an improved alternative for the previously used PMGI process. Measurement of thin films deposited directly on $\mathrm{YBa}_{2} \mathrm{Cu}_{3} \mathrm{O}_{\mathrm{x}-7}$ show that the two dielectrics, $\mathrm{BaTiO}_{3}$ and $\mathrm{Si}_{3} \mathrm{~N}_{4}$, in combination with $\mathrm{YBa}_{2} \mathrm{Cu}_{3} \mathrm{O}_{\mathrm{x}-7}$ show low losses at microwave frequencies. This suggests that the materials are compatible with $\mathrm{YBa}_{2} \mathrm{Cu}_{3} \mathrm{O}_{\mathbf{x}-7}$ and would perform well for their desired role in the switch. The following chapters explain in detail how the experiments were setup, the results that were observed and the conclusions that were derived from the resulting data. Finally, the full step-by-step instructions for the MEM switch fabrication can be found from Appendix B to Appendix M. 


\section{Background}

\subsection{MEM capacitive switch}

\subsubsection{Structure}

A MEM capacitive switch has three basic parts: a suspended metal beam, a dielectric gap, and a metal electrode. These three parts are stacked to form a Metal-Insulator-Metal (MIM) capacitor, as shown in Figure 2.1. The metal beam, normally illustrated at the top of the stack, is the switching mechanism. It is flexible and is able to deflect toward the electrode. The insulator gap is composed of two elements an air gap and a thin film dielectric. Placed between the metals, this insulator serves as a means of isolating the two metals. When the beam is deflected the air gap is removed and the insulator is reduced to only the thin film. At the bottom of the stack lies the metal electrode. The electrode is usually part of the transmission line. In most designs, the thin film dielectric is located on top of the metal electrode. The overlap of the beam and the electrode defines the contact area.

Capacitive switches are fabricated into one of two basic structures. The cantilever (Figure 2.1(a)) is singularly clamped. The metal beam is anchored at one end of the switch while extending freely over the contact area at the other end. The metal-bridge structure (Figure 2.1(b)) is doubly clamped. Anchored at both ends of the metal beam, the contact area is in the middle of the switch. 


\section{Cantilever MEM Switch Structure}

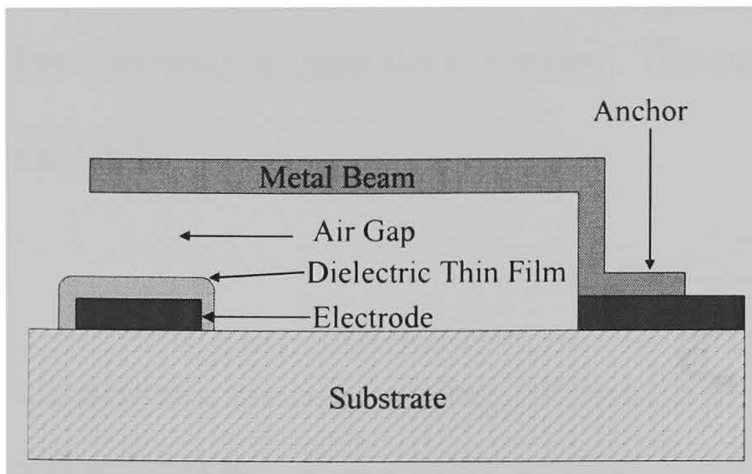

(a)

\section{Air Bridge MEM Switch Structure}

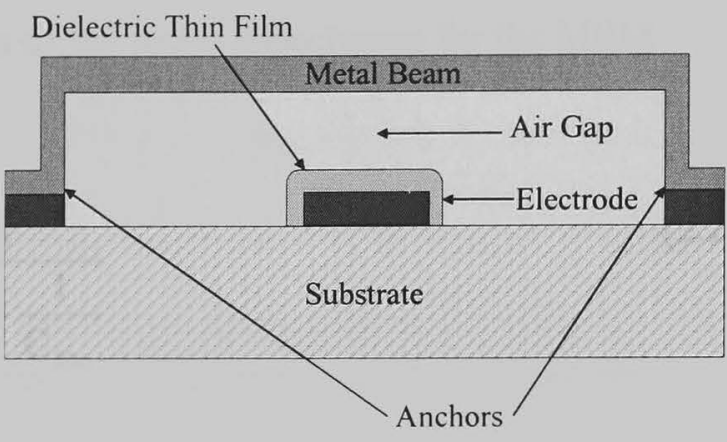

(b)

Figure 2.1 - Diagrams of basic MEM Capacitive Switch Structure. (a) Cantilever Switch Structure (b) Air Bridge Switch Structure

\subsubsection{Operation}

Capacitive switches are operated using electrostatic force. The switch normally rests in the up position. In this position the metal beam holds its natural form suspended over a dual layer insulator composed of air and the thin film dielectric. Applying a bias between the beam and electrode causes charge to build up on both surfaces. This charge exerts a force attracting the two metals. While the electrode is fixed, the beam is free to move, and thus deflects toward the electrode. The deflection causes a change in the capacitance because the air gap thickness is reduced.

The capacitance of the switch goes through a large change during deflection of the metal beam. Using the parallel-plate approximation [7] the switch capacitance can be estimated as

$$
\mathrm{C}=\frac{\epsilon_{\mathrm{o}} \epsilon_{\mathrm{r}} \mathrm{A}}{\mathrm{d}}
$$

where $\epsilon_{\mathrm{o}}$ is the permittivity of vacuum, $\epsilon_{\mathrm{r}}$ is the relative permittivity of the dielectric, $\mathrm{A}$ is the area of the metal plates, and $d$ is the thickness of the dielectric. As previously mentioned, the switch in the up position has a dielectric composed of air and the thin 
film. This scenario, illustrated in Figure 2.2 (a), identifies a simple interpretation of the two elements as capacitors in series. The sum of the series capacitance for the MEM switch is

$$
\mathrm{C}_{\mathrm{up}}=\frac{1}{\frac{1}{\mathrm{C}_{\text {air }}}+\frac{1}{\mathrm{C}_{\mathrm{film}}}}
$$

and reduces to

$$
C_{\text {up }}=\frac{\epsilon_{\mathrm{o}} \mathrm{A}}{\left(\mathrm{d}_{\mathrm{air}}+\frac{\mathrm{d}_{\text {film }}}{\epsilon_{\text {film }}}\right)}
$$

where $d_{\text {air }}$ and $d_{\text {film }}$ are the thickness of the air gap and thin film respectively, and $\epsilon_{\text {film }}$ is the relative permittivity of the thin film. Using a silicon nitride thin film with a thickness of about $0.2 \mu \mathrm{m}$ and dielectric constant between 7 and 8 , the ratio of the thickness to dielectric constant of the thin film is about $.027 \mu \mathrm{m}$. In contrast, the air gap is usually 1 $\mu \mathrm{m}$ to $5 \mu \mathrm{m}$. The air gap is more than an order of magnitude larger than the thin film ratio, so the sum is dominated by the air gap thickness. In equation (2.3), the up capacitance is inversely proportional to the air gap thickness so the larger the air gap the smaller the capacitor. Thus, as the switch is deflected the capacitance rises with the decrease in the air gap. In the down position the switch capacitance is reduced to

$$
\mathrm{C}_{\mathrm{down}}=\frac{\epsilon_{\mathrm{o}} \epsilon_{\mathrm{film}} \mathrm{A}}{\mathrm{d}_{\text {film }}}
$$

Figure 2.2 (b) shows the switch in the down position and demonstrates the change to the capacitance. The relationship between the up and down state capacitance, $\mathrm{C}_{\text {ratio }}$, is used as a figure of merit [15]. This value is expressed as 


$$
\mathrm{C}_{\text {ratio }}=\frac{\mathrm{C}_{\text {down }}}{\mathrm{C}_{\text {up }}}
$$

and reduces to

$$
\mathrm{C}_{\text {ratio }}=\frac{\epsilon_{\mathrm{r}} \mathrm{d}_{\text {air }}}{\mathrm{d}_{\text {film }}}+1
$$

Capacitance ratios exceeding 100 have been reported [9], but a ratio of 70 or greater provides an excellent switch. The impedance of a switch is dominated by the capacitance. Since the impedance determines the RF behavior of the device, the capacitance ratio provides an important characterization of the switch.

\section{Capacitance of Dielectric Gap with Capacitance of Dielectric Gap with Metal Beam in Up Position Metal Beam in Down Position}

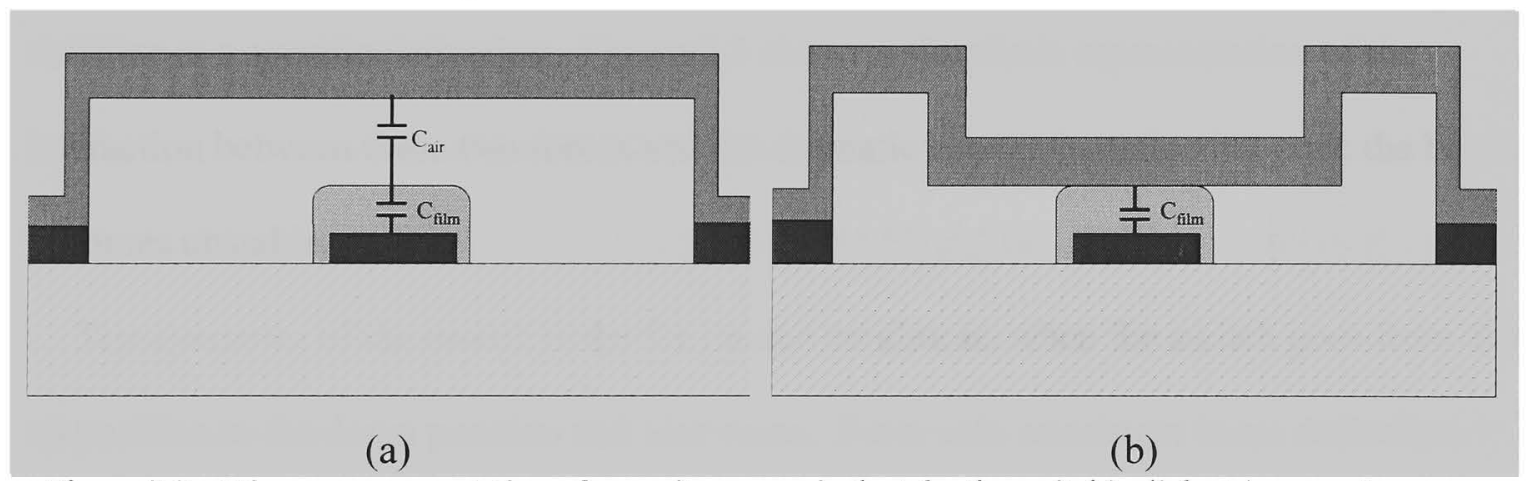

Figure 2.2 - Diagram representation of capacitance equivalent for the switch's dielectric capacitance.

(a) Switch in unactuated, Up State (b) Switch in actuated, down state

The deflection of the switch is a dynamic interaction and is non-linear with respect to voltage. As previously mentioned, the capacitance can be determined based on the dielectric constant and thickness of the insulating material. The application of a voltage to the metal plates causes a charge to form proportional to the capacitance of the structure. The charge exerts a force, $F_{e}$, on the metal beam. $F_{e}$ is directly proportion to the charge; so the larger the charge the more force is applied. This also makes $\mathrm{F}_{\mathrm{e}}$ proportional to the capacitance, since a change in the capacitance results in a change in 
the charge. Given the MEM switch structure $F_{e}$ is a function of both voltage and air gap separation.

Deflection of the beam results in a restoration force, $F_{r}$, that opposes the deformation of the beam and is proportional to the deflection. In the absence of an applied voltage, the beam is at rest and the sum of $\mathrm{F}_{\mathrm{r}}$ and $\mathrm{F}_{\mathrm{e}}$ is zero. Applying a voltage increases $\mathrm{F}_{\mathrm{e}}$ causing deflection, which decreases the air gap. This force is countered by $\mathrm{F}_{\mathrm{r}}$. The deflection also causes an increase in $F_{e}$. If $F_{r}$ can match the increase in $F_{e}$ then the switch remains in the new position. This case is not always true because $F_{e}$ is inversely proportional to the square of the distance. When the rate of change in $\mathrm{F}_{\mathrm{e}}$ due to deflection surpasses the rate of change in $\mathrm{F}_{\mathrm{r}}$ due to deflection, the beam can no longer stabilize at a specific deflection. Figure 2.3 shows a simplistic representation of the interaction between these two forces and the dramatic change in deflection once the beam becomes unstable.

The dynamics of the switch make for unique conditions when the switch goes from the up position to the down position and vise versa. From rest, consistent beam deflection can be achieved in the voltage range labeled "stable," in Figure 2.4 (a). In stable region, switch deflection has a relatively small response increasing capacitance no more than $50 \%$ of the resting value. However, when the switch deflects more than a third of the total air gap, the beam collapses. The voltage at which this happens is predictable and labeled the pull-down voltage. Above the pull-down voltage the switch will always be in the down state. With the collapse of the metal beam onto the dielectric the air gap is removed. Illustrated in Figure 2.4 (b), the switch capacitance increases by 20 to 100 times the rest value. The capacitance changes negligibly below the pull-down voltage 
and does not change once the beam is collapsed above the pull-down. This set of parameters characterizes capacitive switches as bi-stable because the switch has two regions of stability, on and off.

Once deflected, the charge on the metal surfaces will increase with the increase in capacitance. As a result the beam requires very little voltage to hold a charge with a force $F_{e}$ that can overcome $F_{r}$. As illustrated in Figure $2.4(b)$, the voltage must be substantially reduced before the beam is released. The release voltage, similar to the pull-down voltage, can be reliably determined. A hysteresis curve results when the voltage of the switch is ramped up and down slowly. This is advantageous for switching applications where a capacitance change between two large values is desired, but it limits the use of the devices as variable capacitors.

The transmission line also experiences the change in capacitance. A large change in the load of the line enables the manipulation of the RF signal. At low capacitances, the RF signal sees an open circuit, but when the switch actuates and the capacitance increases 20 to 100 times the rest value the RF signal sees a short circuit. In applications, this short may produce either a shunt in the circuit or may connect parts of the circuit. 


\section{Actuator Operation}

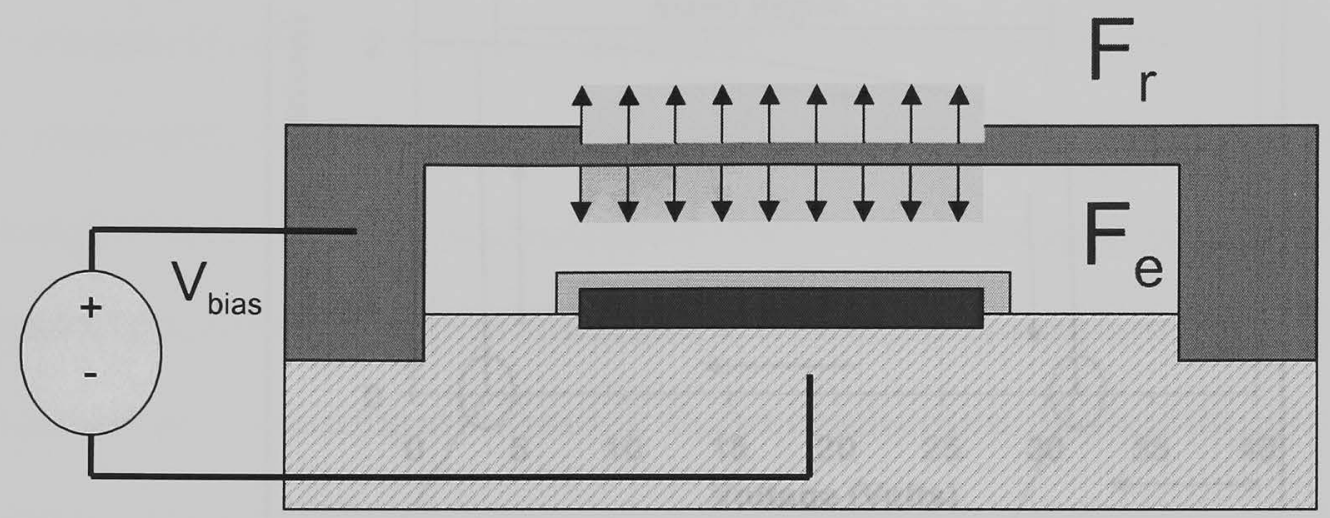

(a)

\section{Deflection As a Function of Bias}

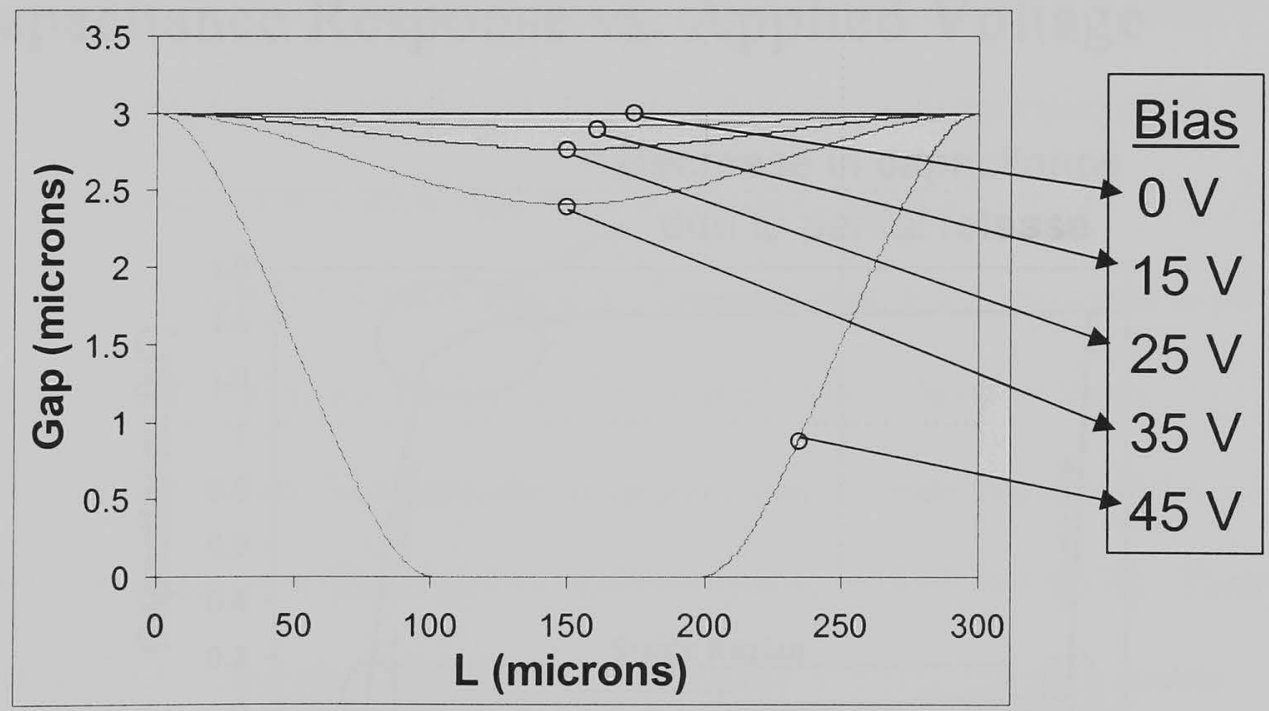

(b)

Figure 2.3 - (a) Illustration of forces at work during actuation of switch. Fr and Fe represent restoration and electrostatic forces respectively. (b) Graph of the deflection of a $300 \mu \mathrm{m}$ beam with varying voltages from $0 \mathrm{~V}$ to $45 \mathrm{~V}$. 


\section{Deflection Hysteresis due to Voltage}

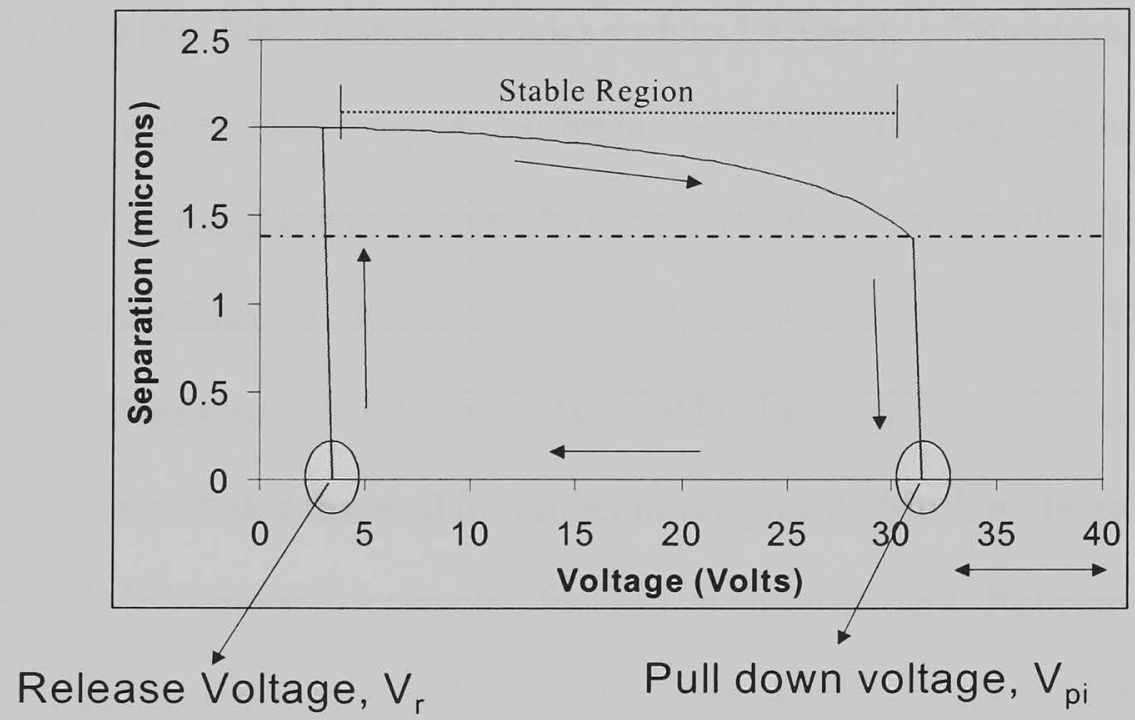

(a)

\section{Capacitance Response vs. Applied Voltage}

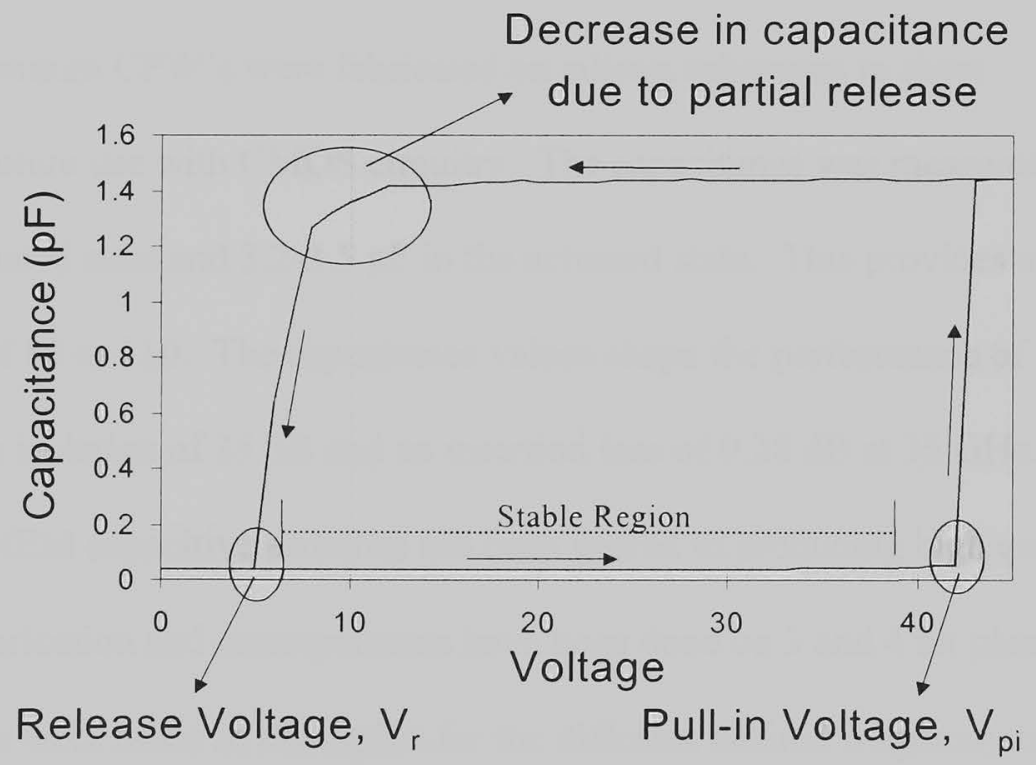

(b)

Figure 2.4 - Typical actuation responses from a MEM Capacitive switch

(a) The deflection at the center of the beam is illustrated as a function of voltage.

(b) The capacitance is plotted with respect to voltage. 


\subsubsection{Published Work}

Research in MEM switch technology is young. The first paper on a MEM switch was published in 1979 [8]. Since then universities such as University of Michigan, Northeastern University, University of California Berkeley, and Georgia Technical Institute and Research and Development labs such as Raytheon, Rockwell, Hughes, and Honeywell have continued to advance MEM switch design and application. With a wide range of proposed uses, such as interconnects, tunable filters, and phase shifters, MEM switches have demonstrated the need for further development. Much of the early development of MEM capacitive switches focused on phase shifters. Refinement of the capacitive switch has lead to models designed for optimal performance at specific RF bands.

Raytheon began work on refining MEM capacitive switches for specific frequency requirements [9]. From this work shunt switches were demonstrated operating at $10 \mathrm{GHz}$ and $35 \mathrm{GHz}$. Aluminum CPW's were fabricated on silicon substrates to show compatibility for future use with CMOS circuitry. The capacitance was measured at 30$40 \mathrm{fF}$ in the unactuated state and 3.2-3.5 pF in the actuated state. This provides a capacitance ratio of 80 to 110 . The capacitance values shape the performance of the switch and provide isolation of $35 \mathrm{~dB}$ and an insertion loss of $0.28 \mathrm{~dB}$ at $35 \mathrm{GHz}$. Their latest research in MEM capacitive switches has been geared to producing high quality phase shifters. Fabrication and measurements have been done on 3 and 4 bit phase shifters. Variations were made in the design for the different desired frequency ranges. Work on X-band [17] and Ka-band [18] phase shifters have shown great potential by outperforming conventional devices such as p-i-n diode and pHEMT switches. The 4-bit 
phase shifter X-band design was reported to have an average insertion loss of $1.4 \mathrm{~dB}$ and return losses less than $-11 \mathrm{~dB}$ at $8 \mathrm{GHz}$, while the Ka-band 4-bit resonant phase shifter has an average insertion loss of $2.25 \mathrm{~dB}$ and less than $-15 \mathrm{~dB}$ return loss at $34 \mathrm{GHz}$.

At the University of Michigan, their approach to the MEM capacitive switch was slightly different from that of Raytheon. The work at Raytheon has mostly been geared to optimizing the MEM capacitive switch and implementing the technology for phase shifters. Rebeiz and others at the University of Michigan found it important to improve the switch performance by incorporating passive devices such as capacitors and inductors. T-match and $\pi$-match shunt switch designs were demonstrated functioning from 75 to $110 \mathrm{GHz}$ [10]. By introducing the capacitive switch in series with the RL-circuit they were able to tune the resonance of the lumped element so that it functions in the W-Band. Their work includes the implementation of similar designs for X-Band $[11][12]$ and Ka-Band circuits [13]. This group has also worked on the design and fabrication of phase shifters [14]. Their results report insertion losses of $1.8 \mathrm{~dB} / 84^{\circ}$ and return loss of $40 \mathrm{~dB}$ at $40 \mathrm{GHz}$. These phase shifters were measured through a wide range of frequencies from close to $\mathrm{DC}$ to $60 \mathrm{GHz}$.

Hilerio's work was focused on fabricating and characterizing a MEM capacitive switch similar to what others were producing in the field. The switch design was fabricated on a CPW circuit and was modeled for operation from $100 \mathrm{MHz}$ to $20 \mathrm{GHz}$. He successfully fabricated and modeled these switches with insertion loss of $0.15 \mathrm{~dB}$ and isolation of $22 \mathrm{~dB}$. By keeping the design simple he was able to model the switch and arrive at measured values that closely matched the actual values. 


\subsubsection{Challenges Relating to Switch}

The engineering of MEM switches is a fairly young technology. Material aspects of micro devices are often treated differently from conventional sized devices. Lifetime, thermal, and electrical considerations must be revisited and modeled for these specific cases.

The fabrication process can be divided into three main sections: photolithography, film deposition, and material etching. Each of the steps posses its own challenges. Photolithography is a method of patterning with the use of masks and light sensitive polymers. The masks can form patterns on the polymers and the polymers can in turn be used to form shapes. With smaller shapes and increasing intricacy in the patterns there is always a need for more precise patterning methods and tools. The deposition of materials ranges from a single element deposition such as gold to complex chemical depositions such as $\mathrm{YBa}_{2} \mathrm{Cu}_{3} \mathrm{O}_{\mathrm{x}-7}$. Besides the variety of compounds, there is a large range of deposition methods including thermal evaporation and sputtering seen in this work. Each deposition process is involved and has many variables that must be considered. In developing an optimal process the multitude of variables can be frustrating and time consuming. An optimal process must take into account both the rate of deposition and the quality of the deposition. Deposition processes may have affects such as the unintended interaction with other materials and damage from heat transfer. These are examples of situations that can be encountered and that must be controlled. Material etching can be found in most fabrication processes. Etching can include cleaning of surfaces as pre-treatment or removal of materials in a liftoff process. These steps must be optimized as well. The idea is to be able to remove the desired material quickly and 
completely. It is not guaranteed that the etchant will not react with other materials. Therefore, research must be done on etchant materials before use to avoid unwanted affects.

These are the most commonly used steps in fabrication of MEM switches but the field changes daily. The advancements in technology bring about new techniques that may be particular to a specific switch fabrication. These techniques may prove to be a better choice and become common practice in the future.

\subsection{HTS}

Superconductors are materials that have a unique behavior at low temperatures. Superconducting materials perform as perfect DC conductors below a specific temperature called the critical temperature $\left(T_{c}\right)$. This temperature varies between materials. Divided into two classes, the materials are considered either Low Temperature Superconductors (LTS) or High Temperature Superconductors (HTS). HTS are considered to have a $T_{c} \geq 0 \mathrm{~K}$ and are usually a copper-oxygen compound.

HTS exhibit other properties that are not usually found in LTS materials [19]. All HTS are type II superconductors. Type I superconductors have two states of operation, either superconducting or not. In contrast, the type II can be found in a mixed state where both superconducting and "normal" states of the material exist. Type I and II superconductors can repel a magnetic field below their specific limit, $\mathrm{H}_{\mathrm{c}}$ and $\mathrm{H}_{\mathrm{c} 1}$ respectively. At field strengths above this limit the type I no longer functions as a superconductor. The type II produce vortices, small circular eddy currents that operate in the normal conduction state of the material. As a result, a portion of the magnetic field penetrates through the HTS while it is still functioning as a superconductor with 
diminished performance, lower $T_{c}$, low critical current $I_{c}$, and high RF impedance. A secondary magnetic field strength, $\mathrm{H}_{\mathrm{c} 2}$, provides the upper limit of operation for the HTS. Other distinguishing characteristics of HTS are larger energy gaps, shorter coherence lengths, and linear DC resistivity.

Physicists K.A. Müller and G. Bednorz wrote the first paper on HTS class of superconductors in 1986 [20]. Their approach to finding a superconductor with a higher $\mathrm{T}_{\mathrm{c}}$ limit than the present $23.2 \mathrm{~K}$ lead them to $\mathrm{La}_{2} \mathrm{Cu}_{3} \mathrm{O}_{4}$ doped with $\mathrm{Ba}^{2+}, \mathrm{Sr}^{2+}$, or $\mathrm{Ca}^{2+}$. Other compounds such as $\mathrm{YBa}_{2} \mathrm{Cu}_{3} \mathrm{O}_{\mathrm{x}-7}$ shortly followed. These materials no longer fit the conventional Bardeen-Cooper-Schrieffer (BCS) theory of superconductivity. The BCS theory was regarded as the complete explanation for the superconductivity phenomena. An explanation that can fully account for how the new mechanisms in these materials work is still among the challenges that exist in the field of HTS presently. Many theories exist, but there is no discernable model that can account for all of the behavior observed in the diverse number of HTS materials.

As some researchers work on developing better models to explain these materials others are exploring areas where these materials can be implemented. The high $T_{c}$ of these films provides a commercially viable material that can function at liquid nitrogen temperature and eliminate the use of more expensive coolants such as liquid helium. As mentioned previously, HTS transition through two states while functioning as superconductors. The second state provides a more gradual transition from superconductivity to normal state. With more practical operation costs and less abrupt phase transition, the HTS group of materials offer material characteristics that a few years ago were not thought possible. 


\subsubsection{Why use $\mathrm{YBa}_{2} \mathrm{Cu}_{3} \mathrm{O}_{x-7}$}

$\mathrm{YBa}_{2} \mathrm{Cu}_{3} \mathrm{O}_{\mathrm{x}-7}$ was the superconductor chosen for the transmission line. Its long history and availability made it the material of choice for this research. $\mathrm{YBa}_{2} \mathrm{Cu}_{3} \mathrm{O}_{\mathrm{x}-7}$ was amongst the first HTS found. Its discovery dates back to 1987 [19]. A large database of literature is available on the material. The works include but are not limited to microwave research of the $\mathrm{YBa}_{2} \mathrm{Cu}_{3} \mathrm{O}_{\mathrm{x}-7} . \mathrm{YBa}_{2} \mathrm{Cu}_{3} \mathrm{O}_{\mathrm{x}-7}$ is used today for tunable filters, high $\mathrm{Q}$ resonators, and superconducting tapes and cables.

One of the most important reasons for choosing $\mathrm{YBa}_{2} \mathrm{Cu}_{3} \mathrm{O}_{\mathrm{x}-7}$ is its availability. At present, research is being performed at FIU's FAST Center using $\mathrm{YBa}_{2} \mathrm{Cu}_{3} \mathrm{O}_{\mathrm{x}-7}$ to produce tunable filters. $\mathrm{YBa}_{2} \mathrm{Cu}_{3} \mathrm{O}_{\mathrm{x}-7}$ depositions are made by pulsed laser deposition (PLD). This deposition method provides quick results but the specimens are left with a rough surface. The FAST Center's thin films vary from the ones grown by Hanscom AFB's AFRL/SNHA group. Work at SNHA has been focusing on fundamental analysis of the non-linearity in superconductors such as $\mathrm{YBa}_{2} \mathrm{Cu}_{3} \mathrm{O}_{\mathrm{x}-7}$. The HTS thin films are deposited by means of magnetron sputtering leaving a smooth surface on the specimens. This method is more frequently used and is considered the established method. The rough surface of the FAST Center specimens creates a larger surface area than the SNHA specimens. This large variation between the two sites was potentially useful for comparison of surface interaction. Both sites could provide specimens within two days notice. The ease in availability and contrast in deposition methods were the main reasons for choosing $\mathrm{YBa}_{2} \mathrm{Cu}_{3} \mathrm{O}_{\mathrm{x}-7}$. 


\subsection{Israel Hilerio's Thesis}

Israel Hilerio, an FIU graduate student, had previously completed work on the fabrication and functionality of a MEM switch for use with RF signals. His thesis covered the fabrication of a capacitive switch as well as modeling and measurement of the switch performance. Switches were fabricated on gold co-planar waveguide (CPW) circuits using GaAs substrates. Use of materials with extensive background information made it easier to compare his switch with current efforts elsewhere.

\subsubsection{Design and relevance to this work}

It was previously mentioned that the work conducted in this paper is in part based on the work completed by Hilerio. By providing a fabrication process, a functional switch and measurements for comparing the switch, Hilerio showed that it is possible to fully develop a MEM switch with the available equipment. In his thesis, he highlighted both the achievements and challenges of his research. The improvement in fabrication relating to these obstacles was part of the motivation for this work.

He suggested that future work focus on the replacement of the conventional conductor, composed of metal, with that of a superconductor. MEM switches from his work showed switch performance comparable to that of other works. As a result, the work showed that MEM switches are the best alternative to the current semiconductor devices used in RF switching applications. The switches require a smaller amount of energy to activate and provide good short and open circuit responses in the RF range. It was clear that by modifying the conductor device losses could be reduced further enhancing the MEM switch advantages over semiconductor devices. 


\subsubsection{Goals Accomplished}

Hilerio's thesis is a good source of background information for anyone who wishes to pursue research on MEM switch fabrication. The work shows that there are clearly two main challenges to the MEM switch. The first challenge is the fabrication of the switch. This includes the equipment and processing steps that are required to produce the switch. The other challenge comes from the improvement of the switch performance. It has been shown that the switch performance is intimately related to the fabrication.

Hilerio's work focused on characterizing a switch based on the fabrication equipment available in the lab. The analysis of the switches showed that further work needed to be done to improve the switch in its mechanical aspects as well as its RF responses. This would involve new designs for the switch and adjustments to the fabrication process to alter the state of the materials either during fabrication or as a post-fabrication process. For example, the metal beam in Hilerio's thesis suffered from stress and strain due to the evaporation process. This was characterized in Hilerio's work and it was suggested that either a different deposition process be used or that a post anneal be attempted to reduce the stress in the metal.

Hilerio's work provides a full fabrication process using the available equipment in the lab. This is important as it allowed for the identification of the instruments needed for the fabrication of the MEM switch and reduced the development time for several of the fabrication steps. The information in his thesis was a valuable asset in the development of this research. 


\section{Experimental Procedures}

\subsection{Switch design and simulation}

\subsubsection{Transmission line possibilities}

This thesis explores the possibility of a MEM switch fabrication process compatible with high temperature superconductors. The switch is designed to operate at microwave frequencies. This means that the superconducting circuit must be treated as a transmission line. There are three basic transmission line types compatible with integrated circuits: the coplanar waveguide, the stripline and the microstrip (Figure 3.1). Each type has specific advantages and limitations that must be taken into consideration. The coplanar waveguide has the simplest fabrication requiring processing on only one surface but results in losses due to moding. Striplines provide the lowest signal distortion but have the most complicated fabrication. Microstrip transmission lines are a compromise between coplanar and stripline structures. They are widely used, provide good signal properties and do not require significantly more processing than the coplanar waveguide. As a result, microstrip transmission lines have become the standard for microwave integrated circuits and the preferred choice for the switch design 


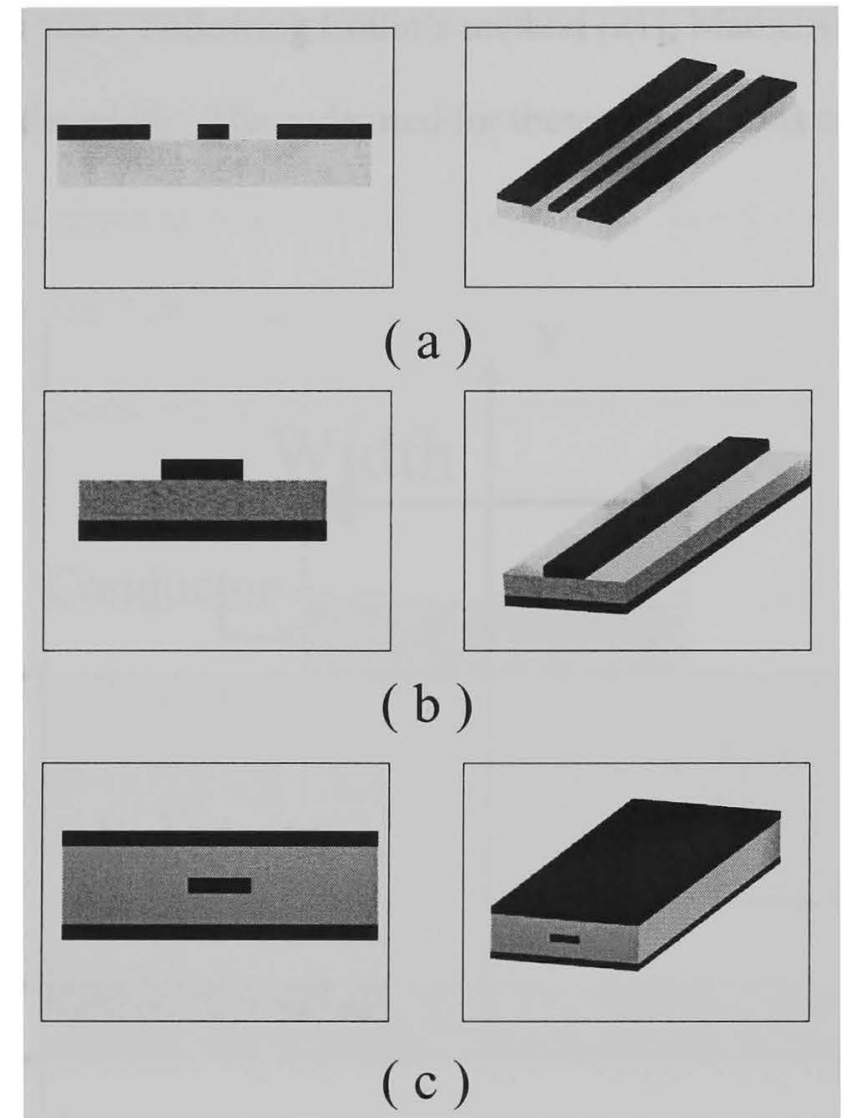

Figure 3.1 - Cross Sectional and 3D View of 3 Types of Transmission Lines. (a) Coplanar Waveguide, (b) Microstrip, (c) Stripline

\subsubsection{Microstrip design process}

The microstrip transmission line will be fabricated using lanthanum aluminate $\left(\mathrm{LaAlO}_{3}\right)$ as the substrate. An $\mathrm{YBa}_{2} \mathrm{Cu}_{3} \mathrm{O}_{\mathrm{x}-7}$ coating on one side of the substrate will provide the ground plane. The opposite side of the substrate will be coated with $\mathrm{YBa}_{2} \mathrm{Cu}_{3} \mathrm{O}_{\mathrm{x}-7}$ and then used to patterned the transmission line and fabricate the MEM switch.

The only consideration in the patterning of the microstrip line is width. The width of the conductor, the relative dielectric permittivity $\epsilon_{\mathrm{r}}$, and thickness of the substrate determine the characteristic impedance $Z_{c}$ of the microstrip (Figure 3.2). The characteristic impedance is an important attribute and for most microwave applications 


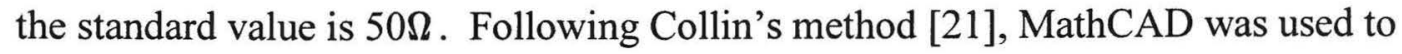
iteratively solve for the width. The code used for these calculations can be found in Appendix A.

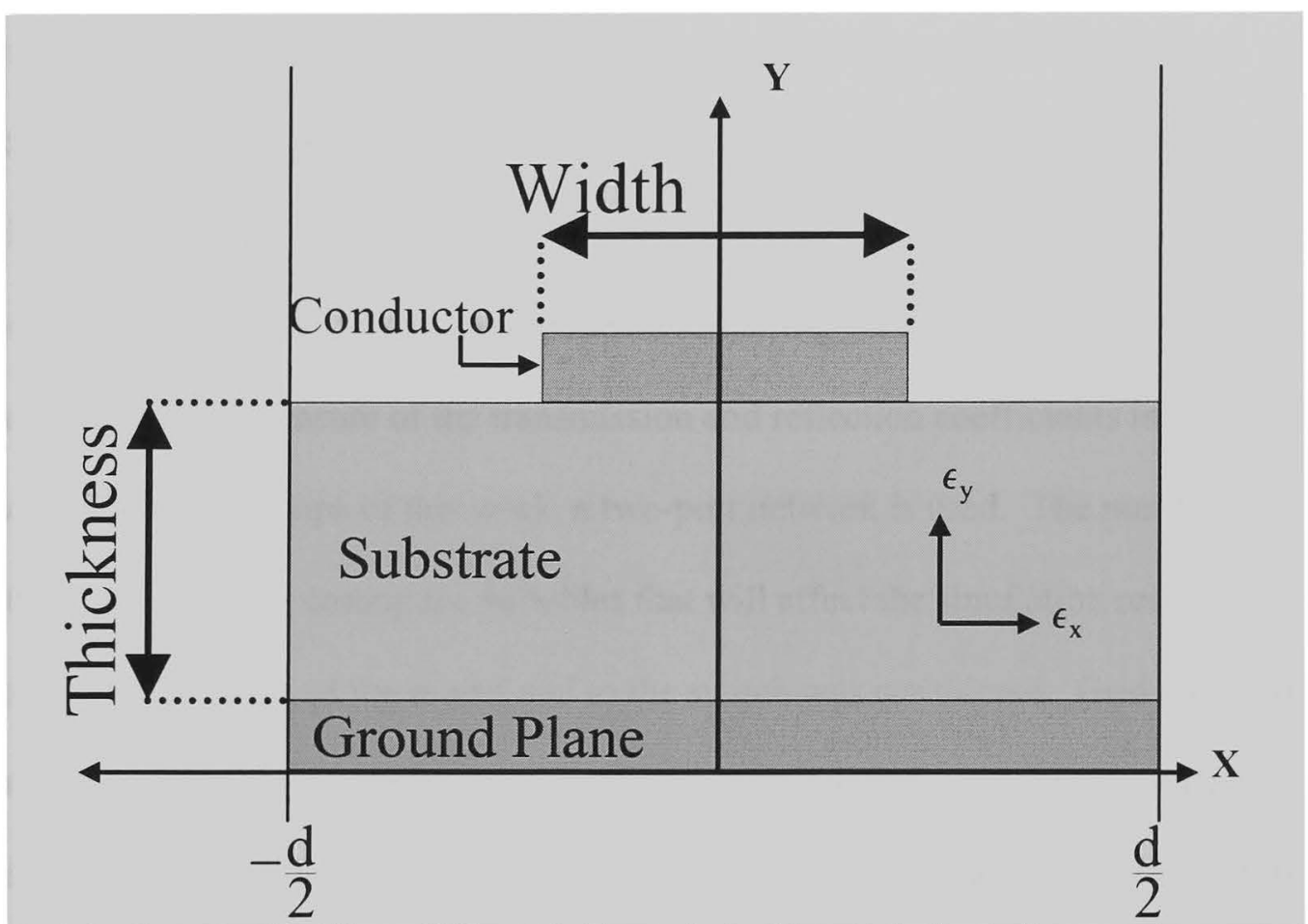

Figure 3.2 - Cross Section View of Microstrip Transmission Line. Labeling indicates major parameters contributing to Characteristic Impedance Zc. Substrate assumed anisotropic so $\epsilon \mathrm{r}=\epsilon \mathrm{y}=\epsilon \mathrm{x}$. Sidewalls assumed to be perfect conductors and width $« \mathrm{~d} / 2$.

\subsubsection{Electromagnetic Simulation}

Electromagnetic calculations and analysis can be performed quickly given today's computers and software packages. It is possible to efficiently prototype several designs and have them modeled with reasonable accuracy and speed. Three circuit designs were considered and simulated for the MEM switch (Figure 3.3). The performance of the switches were compared. The circuit designs did not present much variation in the simulations so all three designs (Figure 3.4) were incorporated on the masks for fabrication. 
Electromagnetic simulations were performed by Sonnet. Sonnet is a full electromagnetic wave simulator. The program package uses a method of calculation known as moments analysis to solve Maxwell's equations for a given layout [22]. This type of calculation is both fast and accurate for the simulation of 2.5 dimensional structures such as the planar type geometric structures of microwave integrated circuits and MEM switches.

Sonnet calculates the frequency dependent scattering parameters of the system. The S-parameters are a measure of the transmission and reflection coefficients in a network [7]. In the scope of this work, a two-port network is used. The number of ports and their positions are among the variables that will affect the simulation results. Port proximity to the edges of the model and to the switch was considered. Grid size was also taken into account since smaller grids provide a higher degree of accuracy while requiring greater computational resources. The S11 and S21 parameters represent the signal response at port 1 and port 2 respectively given an initial signal from port 1 . These parameters are the most important results. For a given signal originating from port 1, S11 and S21 will express the amount of signal that is reflected back to port one and the amount of signal that is seen at port 2 .

A series switch design was used for the MEM switch. This device has two states of operation; an open state and a closed state. An ideal open state should have a very low response observed at port 2 . Therefore, the $\mathrm{S} 21$ parameter should have a large negative value that represents the fraction of the signal received at port 2. The opposite response will be demonstrated by an ideal closed state. S11 response of a series switch should be opposite the S21 response. For example, an open circuit will have a weak S21 and a 
strong S11 response. This results from a mismatch in the network that causes the transmitted signal to be reflected back toward the source, a small signal (weak) will be measured at port 2 while a large signal (strong) is measured at port 1.

\section{Switch Diagram}



Figure 3.3 - MEM switch and circuit design chosen for fabrication. Diagram includes typical dimensions for the switch and transmission line. (a) Two dimensional top view of the switch. (b) Angled 3 dimensional rendering of switch. 


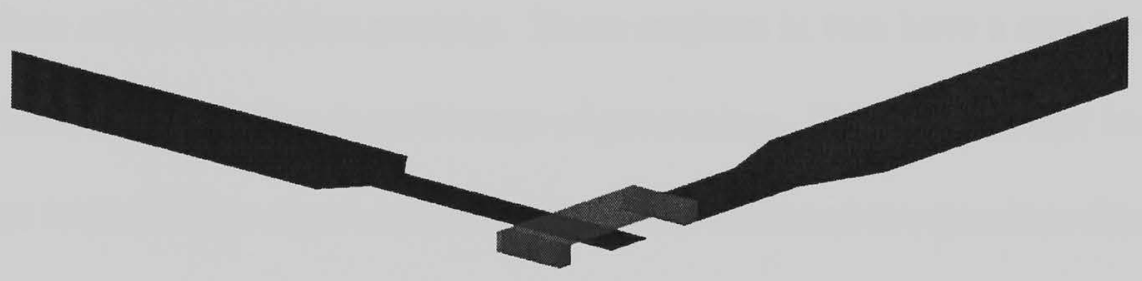

(a)

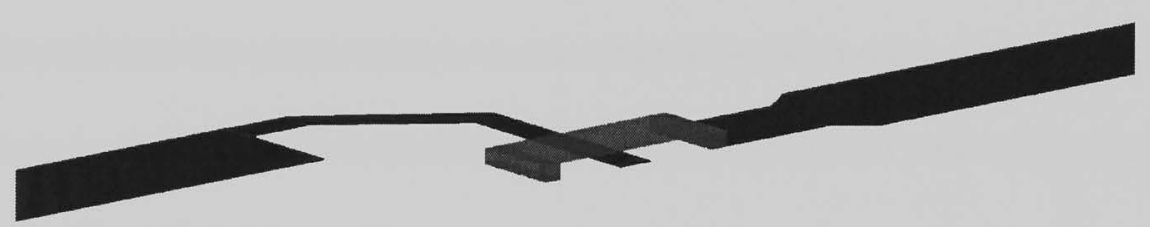

(b)

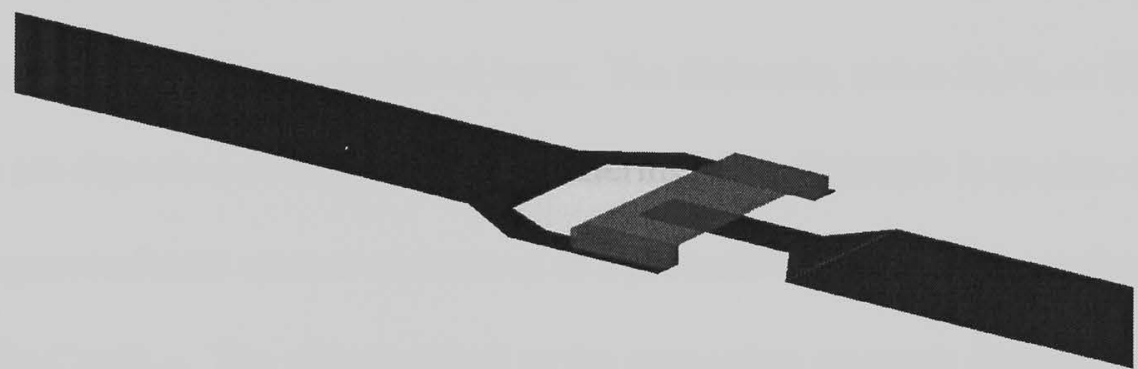

(c)

Figure 3.4 - Three different designs considered for MEM switch circuit 


\subsection{Switch Fabrication}

\subsubsection{Process Flow}

The process flow is an outline of the switch fabrication process. It is divided into major sections of the fabrication process. These sections in turn have a step-by-step account of what must be done in each stage of processing. The process flow is extremely important as it dictates the exact order that should be followed to reproduce the desired results for a given stage in the switch fabrication. The process flow for the fabrication of a MEM switch with an HTS thin film is shown in Figure 3.5. The switch fabrication starts with a $\mathrm{LaAlO}_{3}$ substrate coated with $\mathrm{YBa}_{2} \mathrm{Cu}_{3} \mathrm{O}_{\mathrm{x}-7 .}$. The first mask, "YBCO Layer," is used to pattern the microstrip circuit using photoresist. The $\mathrm{YBa}_{2} \mathrm{Cu}_{3} \mathrm{O}_{\mathrm{x}-7}$ is etched using acetic acid and the photoresist is removed leaving behind the desired pattern. The circuit pattern is recoated with a dual layer photoresist-LOR and patterned using the second mask, "Sacrificial Layer."

Using positive resist, Shipley S1813, with the Sacrificial Layer mask will develop an image on the photoresist identical to the mask pattern. This image is an inverted pattern of the final deposited material, thus exposing the contact areas for deposition of the dielectric coating and silicon sacrificial layer. The dielectric, either $\mathrm{Si}_{3} \mathrm{~N}_{4}$ or $\mathrm{BaTiO}_{3}$, and the silicon are deposited in-situ using RF-sputtering. The dielectric is used to avoid a metal to superconductor contact and serves as a protective coating between the silicon and the $\mathrm{YBa}_{2} \mathrm{Cu}_{3} \mathrm{O}_{\mathrm{x}-7}$. The silicon serves as the supporting structure during the deposition of the metal beam. Performing a lift-off will remove the S1813-LOR, leaving behind the contact pattern composed of a silicon deposition stacked on top of a dielectric deposition. The final mask, "Metal Layer," is used with the S1813-LOR. The pattern leaves the end 
contact points and the metal beam pattern exposed for deposition. Gold is then deposited and patterned with a lift-off process. Finally, the device is etched using $\mathrm{XeF}_{2}$ to remove the silicon. Removing the silicon concludes the fabrication leaving an air bridge structure as the switch.

Many sections of the process fabrication were independent of each other. This allowed for steps to be worked on individually. Once successful, the steps were modified slightly to fit the prescribed layout.

While this effort is based on the work of Hilerio [1], the process has been modified and improved. In particular, the sacrificial layer used in Hilerio's work was PMGI. This has been replaced with a silicon sacrificial layer. The reasons are discussed below. In addition, a new dual layer polymer process using LOR was introduced. 


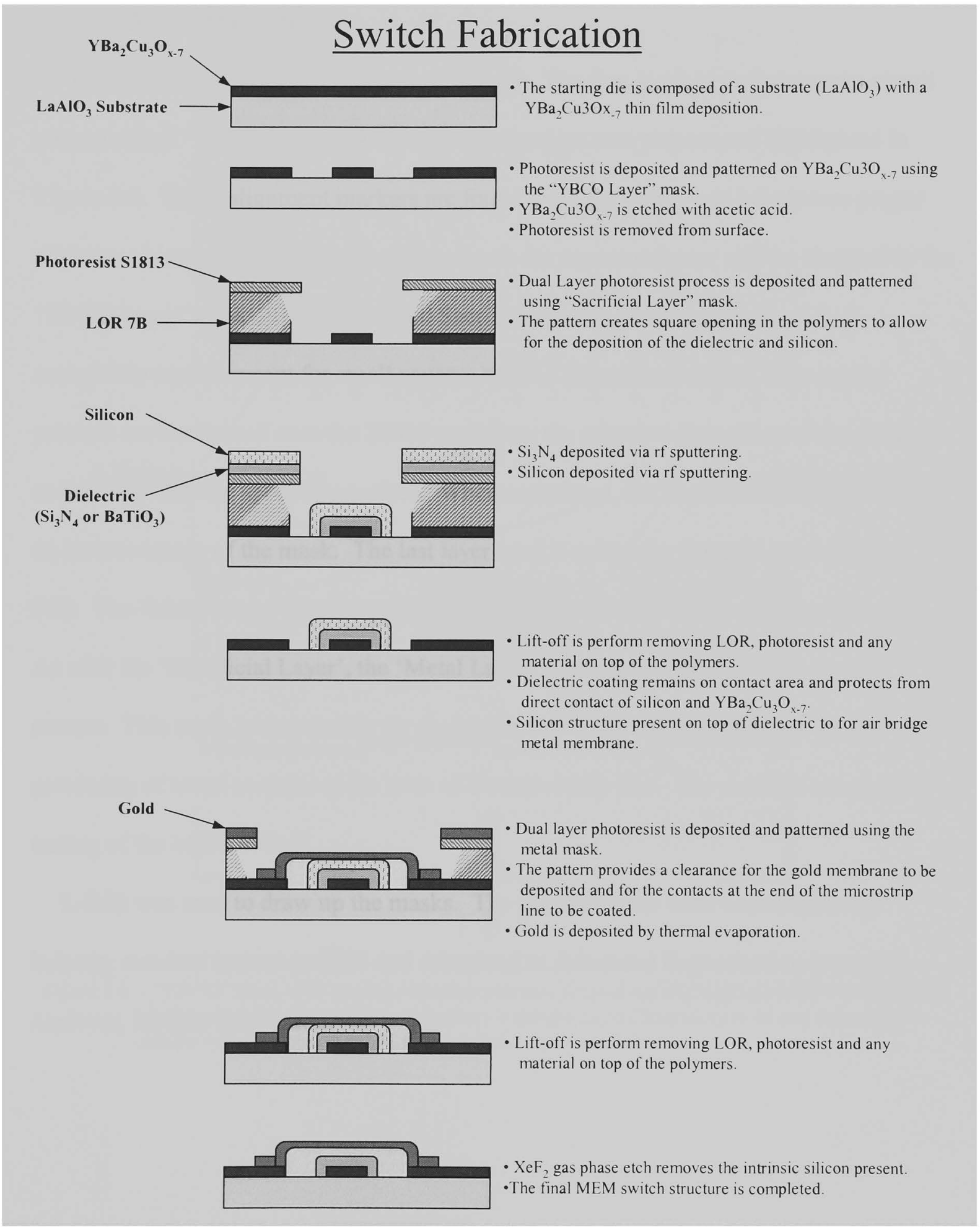

Figure 3.5 - Switch Fabrication Steps 


\subsubsection{Mask Design}

The fabrication process requires three masks. The first mask is the microstrip circuit pattern called 'YBCO Layer'. Alignment markers are also present and highlighted in Figure 3.6. These alignment markers are found in all the masks and help insure proper alignment between layers. The pattern seen on the superconductor will be identical to the 'YBCO Layer' mask. The 'Dark Field Sacrificial' mask, shown in Figure 3.7, is completely coated except for small squares and the alignment markers. The square patterns are transposed onto the $\mathrm{S} 1813$ and allow the selective deposition of the dielectric and silicon onto the specimen surface. When completed, the deposited materials will be an inverse image of the mask. The last layer used is called the 'Metal Layer' (Figure 3.8). The 'Metal Layer' mask supplies a template that is used to create the gold beam. As with the 'Sacrificial Layer', the 'Metal Layer' is a negative image of the desired pattern. This mask is responsible for the length and width of the gold beam for the patterning of metal contacts at the ends of the microstrip line. The contacts are used for testing of the MEM switch.

L-Edit was used to draw up the masks. The mask patterns were converted to an industry standard known as GDS and submitted to Advanced Reproduction located in Andover, MA for fabrication. 


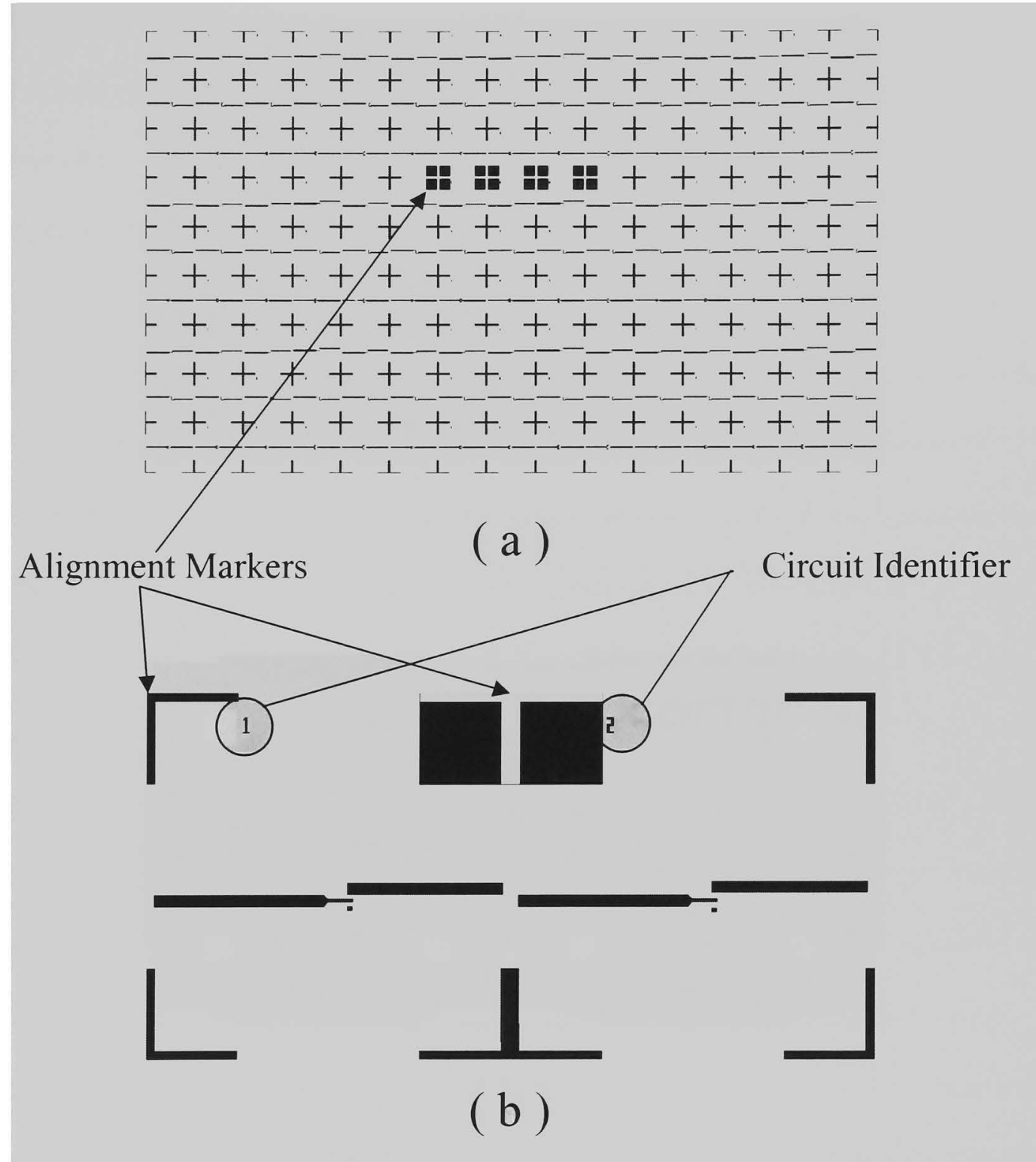

Figure 3.6 - "YBCO" Mask with several alignment markers pointed out and highlighted(a) View of full mask pattern with four alignment markers highlighted.(b) Close up view of two microstrip circuits with the separating alignment marker highlighted. 